RESPIRATORY PHYSIOLOGY

\title{
Effects of breathing pattern and inspired air conditions on breath condensate volume, $\mathrm{pH}$, nitrite, and protein concentrations
}

\author{
J B McCafferty, T A Bradshaw, S Tate, A P Greening, J A Innes
}

Thorax 2004;59:694-698. doi: 10.1136/thx.2003.016949

See end of article for authors' affiliations

....................

Correspondence to: Dr J McCafferty, Respiratory Unit, Western General Hospital, Crewe Road, Edinburgh' EH2 4XU, UK; john. mccafferty@ed.ac.uk

Received 5 October 2003 Accepted 14 April 2004

\begin{abstract}
Background: The effects of breathing pattern and inspired air conditions on the volume and content of exhaled breath condensate $(E B C)$ were investigated.

Methods: Total exhaled water (TEW), EBC volume, $\mathrm{pH}$, nitrite and protein concentrations were measured in three groups of 10 healthy subjects breathing into a condenser at different target minute ventilations $(\mathrm{Vm})$, tidal volumes $(\mathrm{Vt})$, and inspired air conditions.

Results: The volumes of both TEW and EBC increased significantly with $\mathrm{Vm}$. For $\mathrm{Vm} 7.5,15$ and $22.5 \mathrm{I} /$ min, mean (SD) EBC was $627(258) \mu l, 1019(313) \mu l$, and $1358(364) \mu l$, respectively $(p<0.001)$ and TEW was $1879(378) \mu l, 2986(496) \mu l$, and 4679 (700) $\mu$, respectively $(p<0.001)$. TEW was significantly higher than $\mathrm{EBC}$, reflecting a condenser efficiency of $40 \%$ at a target $\mathrm{Vm}$ of $7.5 \mathrm{I} / \mathrm{min}$ which reduced to $29 \%$ at $\mathrm{Vm} 22.5 \mathrm{l} / \mathrm{min}$. Lower $\mathrm{Vt}_{t}$ gave less TEW than higher $\mathrm{V}_{t}(26.6 \vee 30.7 \mu \mathrm{l} / \mathrm{I}$, mean difference $4.1(95 \% \mathrm{Cl} 2.6$ to 5.6$), \mathrm{p}<0.001)$ and a smaller EBC volume $(4.3 \vee 7.6 \mu \mathrm{l} / \mathrm{l}$, mean difference $3.4(95 \% \mathrm{Cl} 2.3$ to 4.5$), \mathrm{p}<0.001)$. Cooler and drier inspired air yielded less water vapour and less breath condensate than standard conditions $(p<0.05)$. Changes in the breathing pattern had no effect on $\mathrm{EBC}$ protein and nitrite concentrations and $\mathrm{pH}$.

Conclusion: These results show that condensate volume can be increased by using high $\mathrm{Vt}$ and increased $\mathrm{Vm}$ without compromising the dilution of the sample.
\end{abstract}

$\mathrm{E}$ xhaled breath condensate (EBC) has been proposed as a non-invasive means of measuring airway inflammation. Unlike traditional methods of sampling secretions from the lower respiratory tract such as bronchoalveolar lavage, EBC analysis has the advantage of being simple to perform, may be repeated frequently, and can be applied to patients during both the stable and exacerbation phase of disease. The condensate derives from expired water vapour and volatile gases, but the presence of non-volatile solutes suggests that droplets of airway lining fluid have also been collected due to aerosolisation during turbulent airflow. Analysis of these solutes may potentially provide insights into the pathophysiology of lung diseases such as asthma, ${ }^{1-3}$ cystic fibrosis, ${ }^{45}$ and chronic obstructive pulmonary disease. $^{67}$

While EBC shows promise as a source for biomarkers in pulmonary diseases, large variability has been reported in the concentration of solutes in EBC samples with considerable overlap between normal subjects and disease groups. ${ }^{4-7}$ In the absence of supporting data, much of this has been attributed to variations in the proportion of water vapour diluting the airway lining fluid or variations in flow affecting the amount of aerosolised solute. The dilution effect was recently studied by Effros et $a l^{8}$ who sought to quantify this by measuring ion concentrations in EBC. By assuming the airway lining fluid to be isosmolar to plasma, they estimated that variations in dilution may affect analyte concentrations by a factor of up to 100 or more. Previous studies of respiratory pattern and breath condensate have been inconclusive. Schleiss et al ${ }^{9}$ found that the concentration of the volatile solute hydrogen peroxide was dependent on flow rate, whereas Montuschi et $a l^{10}$ found 8-isoprostane levels to be independent of flow rate. They also found a high degree of variability in repeated samples even under controlled conditions, suggesting a mechanism other than dilution as a cause.
Although the major determinant of exhaled water vapour volume is minute ventilation $(\mathrm{Vm})$ and duration of collection, ${ }^{11}$ the effect of differences in ventilatory pattern (such as tidal volume $(\mathrm{Vt})$ ) has not been quantified. It is also well established that cooler and drier inspired air produces a lower concentration of water vapour in the exhaled breath, ${ }^{12}$ yet this has not been quantitatively assessed in the context of EBC collection.

The aim of this study was therefore to determine the effect of ventilatory pattern ( $\mathrm{Vm}$ and $\mathrm{Vt}$ ) and inspired air conditions on the volume of condensate collected and the concentration of certain non-volatile solutes (nitrite and protein) and $\mathrm{pH}$ in EBC.

\section{METHODS}

\section{Collection of EBC}

EBC was collected on a commercial breath condenser (EcoScreen, Jaeger, Germany). Samples were collected in interchangeable sampling tubes (one per sample) with subjects breathing (with nose clip) through a non-rebreathing two way valve. All sampling tubes were disinfected for 30 minutes using $1 \%$ potassium monopersulphate solution (Virkon, Antec International Ltd, UK), rinsed for 2 hours by flushing with tap water, then rinsed with ultrapure water (ELGA Labwater, UK) and air dried prior to use. Samples were centrifuged (2000 rpm, 2 minutes) before measurement of volume, immediately frozen, and stored refrigerated at $-80^{\circ} \mathrm{C}$.

\section{$\mathrm{pH}$ of EBC}

The $\mathrm{pH}$ of the EBC was measured immediately after collection (without deaeration) using a calibrated $\mathrm{pH}$ meter

Abbreviations: EBC, exhaled breath condensate; TEW, total exhaled water; $\mathrm{Vm}$, minute ventilation; $\mathrm{Vt}$, tidal volume 
incorporating an ISFET sensor with temperature compensation (model KS723, Camlab, Cambridge, UK) with an accuracy of $\pm 0.1 \mathrm{pH}$.

\section{EBC nitrite concentration}

The nitrite concentration was determined by a colorimetric assay based on the Griess reaction ${ }^{13}$ in which triplicates of $100 \mu \mathrm{l}$ EBC were reacted with $25 \mu \mathrm{l}$ Griess reagent and measured at absorbance of $570 \mathrm{~nm}$ with a microplate reader (MR 710, Dynatec). Assay sensitivity was $0.5 \mu \mathrm{mol} / \mathrm{l}$. Samples were stored in polypropylene containers and analysed within 4 weeks to minimise contamination and problems of instability.

\section{EBC protein concentration}

The protein concentration was measured based on the bicinchoninic acid method using a commercially available protein assay reagent kit (Micro BCA Protein Assay, Pierce, Rockford, IL, USA). Assay sensitivity was $0.5 \mu \mathrm{g} / \mathrm{ml}$.

\section{Measurement of flow, temperature, and humidity}

To control and test for the effects of inspired air temperature and humidity the breath condenser was attached to a custom built device housing temperature, humidity, and flow sensors as shown in fig 1. Subjects breathed through a two way valve with temperature and humidity sensors located on the inspiratory and expiratory sides allowing measurement of the condition of the air inspired and the moisture content of the exhaled breath. Inspired air was supplied in a flow-past configuration from an air conditioning unit providing control over the air temperature and moisture content. Temperature sensors were K-type thermocouples (accuracy $\pm 0.1^{\circ} \mathrm{C}$ ). Humidity sensors were of thermoset polymer capacitance construction (accuracy of $\pm 2 \%$, Model HIH-3602-A, Honeywell, USA). Expiratory flow was measured using an ultrasonic phase shift flow meter (Model FR-413, BRDL, Birmingham, UK). The linearity of the sensor was $<2 \%$ and the residual error due to temperature variation $<1 \%$ in the temperature range $0-40^{\circ} \mathrm{C}$. Together these measurements make possible calculation of the total quantity of exhaled water (TEW, see below).

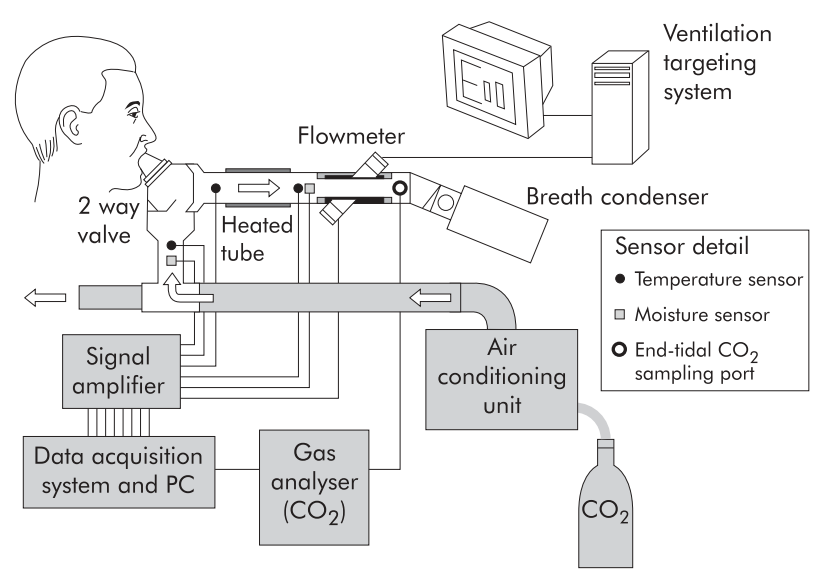

Figure 1 Schematic of apparatus and instrumentation for measurement of total exhaled water and collection of exhaled breath condensate. Subjects breathe through a non-rebreathing two way valve at a pattern set by the ventilation targeting system which generates an audiovisual feedback signal setting ventilatory rate and expiratory flow, respectively. An air conditioning unit controls the temperature and moisture content of the inspired air. Temperature and humidity sensors are located as shown.

\section{Ventilation pattern targeting}

Ventilatory patterns were set by feeding the expiratory flow signal into a PC with purpose built breath targeting software which generated a visual and auditory target for expiratory flow rate and respiratory rate, respectively. Inspiratory to expiratory ratio was set at unity. Eucapnia was maintained at the higher minute ventilations by measuring end tidal $\mathrm{CO}_{2}$ and adding $\mathrm{CO}_{2}$ in the inspirate as necessary.

Thermocouple and humidity sensor output was conditioned by purpose built multichannel amplifiers. All signals were captured on a 16-channel computerised data acquisition system (Model 1401, CED, Cambridge, UK) which interfaced with software (Spike 2, CED, Cambridge, UK) to allow real time signal display and storage of data to disk.

\section{Effect of additional circuit and instrumentation on EBC collection}

To assess any effects from the added dead space associated with the flow meter and other instrumentation, EBC collections were taken at equivalent ventilatory patterns with 10 subjects breathing directly through the standard two way non-rebreathing valve attached to the breath condenser alone and flow measured at the expiratory port of the condenser.

\section{Effects of breathing pattern on EBC collection}

To test the effect of Vm, EBC was collected from 10 healthy non-smoking subjects over timed 6 minute intervals at three target Vm values (table 1 , protocol 1 ), each at high and lower target Vt. The conditions of the inspired air were measured and maintained at $22^{\circ} \mathrm{C}$.

To test the effects of Vt, EBC was collected from 10 healthy non-smoking subjects over timed 6 minute intervals for a fixed target $\mathrm{Vm}$ at high and low target Vt patterns at an inspired temperature of $7^{\circ} \mathrm{C}$.

\section{Effect of inspirate temperature and humidity}

At a fixed ventilatory pattern (Vt $1500 \mathrm{ml}, 10$ breaths/min), 6 minute collections of EBC were taken with 10 subjects breathing warm room air $\left(20^{\circ} \mathrm{C}\right)$ and colder, drier air $\left(9^{\circ} \mathrm{C}\right)$ (table 1, protocol 3).

\section{Analysis of data}

Total exhaled water $(\mu \mathrm{l})$ for each 6 minute collection period was calculated as:

$$
\mathrm{TEW}=\frac{\rho_{\mathrm{a}}}{\rho_{\mathrm{w}}} \mathrm{V}_{\mathrm{T}} \mathrm{W}
$$

where $\mathrm{w}=$ absolute humidity of exhaled air $(\mathrm{g} / \mathrm{kg}), \mathrm{VT}=$ total respired volume (litres ATPS from integrated flow meter signal $), \rho_{\mathrm{a}}=$ air density $\left(20^{\circ} \mathrm{C}\right)$, and $\rho_{\mathrm{w}}=$ water density $\left(20^{\circ} \mathrm{C}\right)$. The absolute humidity of expired air was derived from the mean temperature and moisture sensor signal (measuring relative humidity) which were referred to the physical properties of moist air at atmospheric pressure.

Statistical analysis was performed using SigmaPlot 2001 for Windows version 8.0 and Sigmastat 2001 for Windows (SPSS Science Inc, USA). Paired $t$ tests were used to compare the EBC data and a value of $\mathrm{p}<0.05$ was considered significant. Two way ANOVA was used for the analysis of Vm data and Friedman's two way analysis of variance for data which were not normally distributed (Minitab release 14, Statistical Software, Minitab Inc, USA) was used for the relationship between ventilation and EBC protein, nitrite, and $\mathrm{pH}$.

Study approval for tests on human subjects was granted by the Lothian regional ethics committee and consent was obtained from all participating subjects. 


\begin{tabular}{|c|c|c|c|c|c|c|}
\hline \multirow[b]{2}{*}{$\begin{array}{l}\text { Protocol } \\
\text { no }\end{array}$} & \multirow[b]{2}{*}{$\begin{array}{l}\text { No of } \\
\text { subjects }\end{array}$} & \multirow[b]{2}{*}{$\begin{array}{l}\text { Mean } \\
\mathrm{FEV}_{1} \text { (I) }\end{array}$} & \multicolumn{2}{|c|}{ Target ventilation paftern } & \multicolumn{2}{|c|}{ Inspired air conditions } \\
\hline & & & $\mathrm{Vt}(\mathrm{ml})$ & Vm (I) & $\begin{array}{l}\text { Temperature } \\
\text { ( } \mathrm{C} \text { ) }\end{array}$ & $\begin{array}{l}\text { Moisture content } \\
\text { (mg/g) }\end{array}$ \\
\hline 1 & 10 & 3.9 & $\begin{array}{r}1500 \\
750\end{array}$ & $\begin{array}{l}7.5,15,22.5 \\
7.5,15,22.5\end{array}$ & $22(1.2)$ & $6(0.3)$ \\
\hline 2 & 10 & 3.9 & $\begin{array}{r}1500 \\
500\end{array}$ & $\begin{array}{l}15 \\
15\end{array}$ & $7(0.5)$ & $5.6(0.2)$ \\
\hline 3 & 10 & 3.6 & 1500 & 15 & $\begin{aligned} 20 & (1.8) \\
9 & (1.8)\end{aligned}$ & $\begin{array}{l}9(1.1) \\
5(0.5)\end{array}$ \\
\hline
\end{tabular}

\section{RESULTS}

Effect of additional circuit and instrumentation on EBC collection

No difference was found in the volume of EBC or the $\mathrm{pH}$, nitrite and protein concentrations when subjects breathed with or without the instrumented tubing section joined to the condenser based on paired $t$ tests where a p value of $>0.05$ was not considered statistically significant (EBC: $1155 \mu \mathrm{l}$ with and $1029 \mu \mathrm{l}$ without, mean difference $136 \mu \mathrm{l}$ (95\% CI -14 to 286$)$; pH: $6.3 v 6.4$, mean difference 0.1 (95\% CI -0.15 to 0.35 ); nitrite: $4.1 \vee 4.0$, mean difference 0.1 (95\% CI -0.72 to 0.92 ); protein: $8.1 \vee 5.1$, mean difference 3.5 (95\% CI -0.3 to 7.3$)$ ).

\section{Effect of Vm on TEW}

For target Vm values of 7.5, 15 and $22.5 \mathrm{l}$ (all at Vt $1.5 \mathrm{l}$ ), subjects achieved mean (SD) values of 8.6 (1.95), 15.1 (2.55), and 22.8 (3.27) l/min, respectively. The effect of Vm on TEW and EBC volumes is shown in fig 2. These data were analysed using two way analysis of variance with repeated measures and Tukey's method for multiple comparisons. For all values of $\mathrm{Vm}$ the volume of TEW was significantly greater than the EBC volume $(p<0.001)$. For both TEW and EBC there was a significant increase in volume with increased $\operatorname{Vm}(\mathrm{p}<0.05)$. The volume of TEW rose significantly more with Vm than did the volume of EBC $(\mathrm{p}<0.001)$.

For Vm values of $7.5,15$ and $22.5 \mathrm{l} / \mathrm{min}$ the mean (SD) volume of EBC was 627 (258) $\mu \mathrm{l}, 1019$ (313) $\mu \mathrm{l}$, and 1358 (364) $\mu$ l, respectively $(\mathrm{p}<0.001)$ and the volume of TEW was 1879 (378) $\mu \mathrm{l}, 2986$ (496) $\mu \mathrm{l}$, and 4679 (700) $\mu \mathrm{l}$, respectively

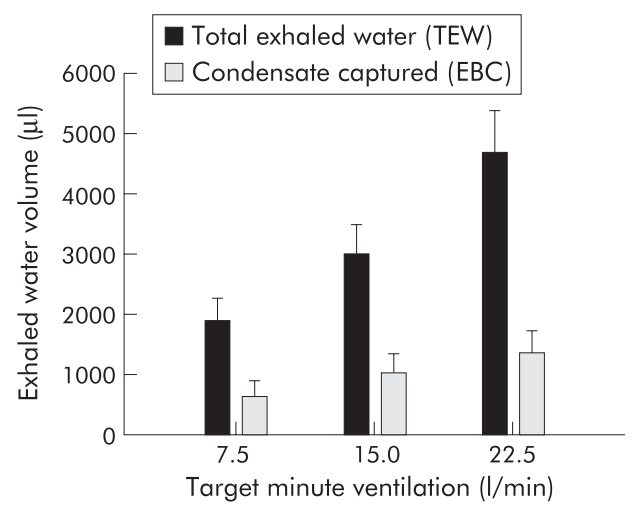

Figure 2 Volumes of total exhaled water (TEW) and exhaled breath condensate $(E B C)$ collected from 10 subjects breathing at three minute ventilation $(\mathrm{Vm})$ targets. Using two way analysis of variance with repeated measures and Tukey's method for multiple comparisons, the volume of TEW was significantly greater than the EBC volume at all values of $\mathrm{Vm}(p<0.001)$. For both TEW and EBC there was a significant increase in volume with increasing $\mathrm{Vm}(p<0.05)$. The volume of TEW rose significantly more with increased $\mathrm{Vm}$ than did the volume of EBC $(p<0.001)$. Limits denote standard error of the mean. $(\mathrm{p}<0.001)$. Water vapour availability (TEW) was significantly higher than EBC, giving a condenser efficiency of $40 \%$ at $\mathrm{Vm}$ $7.5 \mathrm{l} / \mathrm{min}$ which decreased to $29 \%$ at $\mathrm{Vm} 22.5 \mathrm{l} / \mathrm{min}$.

\section{Effect of Vt at fixed $\mathrm{Vm}$}

For target Vt values of $500 \mathrm{ml}$ and $1500 \mathrm{ml}$, subjects achieved actual target volumes of 578 (98) $\mathrm{ml}$ and 1540 (232) $\mathrm{ml}$. The effect of Vt is shown in fig 3 where lower Vt patterns gave significantly less TEW (per litre respired) than higher $\mathrm{Vt}$ (26.6 $v 30.7 \mu \mathrm{l} / \mathrm{l}$, mean difference 4.1 (95\% CI 2.6 to 5.6 ), $\mathrm{p}<0.001)$. This was also reflected in the volume of $\mathrm{EBC}$ collected ( $4.3 \vee 7.6 \mu \mathrm{l} / \mathrm{l}$, mean difference 3.4 (95\% CI 2.3 to $4.5), \mathrm{p}<0.001)$.

\section{Effect of inspired air conditions}

Subjects breathing at equivalent ventilatory patterns but with cooler, drier inspirate were found to yield less water vapour (TEW $33.4 v 35.6 \mu \mathrm{l} / \mathrm{l}$, mean difference $2.2 \mu \mathrm{l} / \mathrm{l}$ (95\% CI 0.2 to $4.2), \mathrm{p}<0.05$ ) and less breath condensate (EBC $8.6 v 10.1 \mu \mathrm{l} / \mathrm{l}$, mean difference $1.5 \mu \mathrm{l} / \mathrm{l}$ (95\% CI 0.3 to 2.7$), \mathrm{p}<0.05$ ).

\section{Effect of ventilatory pattern on exhaled $\mathrm{pH}$, nitrite and protein}

Despite the effects of Vm and Vt on condensate volume (figs 2 and 3 ), the ventilatory pattern had no significant effect on condensate $\mathrm{pH}$, nitrite and protein concentrations using Freidman's two way analysis of variance (since data were not normally distributed). Overall mean (SD) concentrations of protein and nitrite in the EBC were 6.0 (3.4) $\mu \mathrm{g} / \mathrm{ml}$ and 3.9 (2.2) $\mu \mathrm{M}$, respectively, and $\mathrm{pH}$ was 6.3 (0.3); fig 4 .

\section{DISCUSSION}

The volumes of both TEW and EBC increased significantly with Vm. The volume of EBC varied between $627 \mu \mathrm{l}$ and

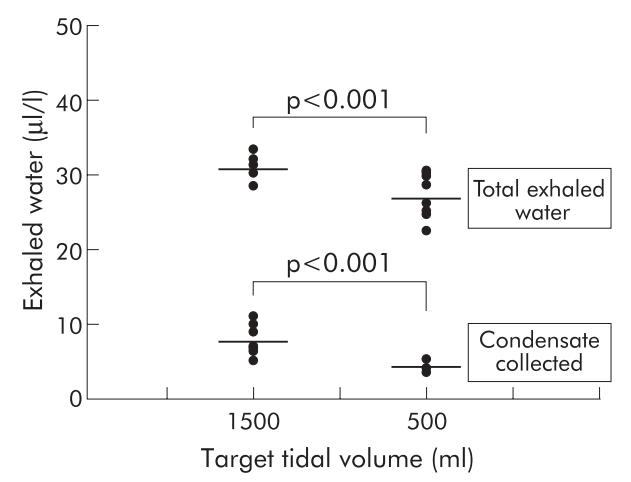

Figure 3 Effect of tidal volume $(\mathrm{Vt})$ on measured volumes of exhaled water and breath condensate. At lower $\mathrm{Vt}$ subjects yielded less exhaled water and breath condensate per litre respired for the same minute ventilation; $p$ values denote the level of significance based on paired $t$ tests. Limits denote standard error of the mean. 


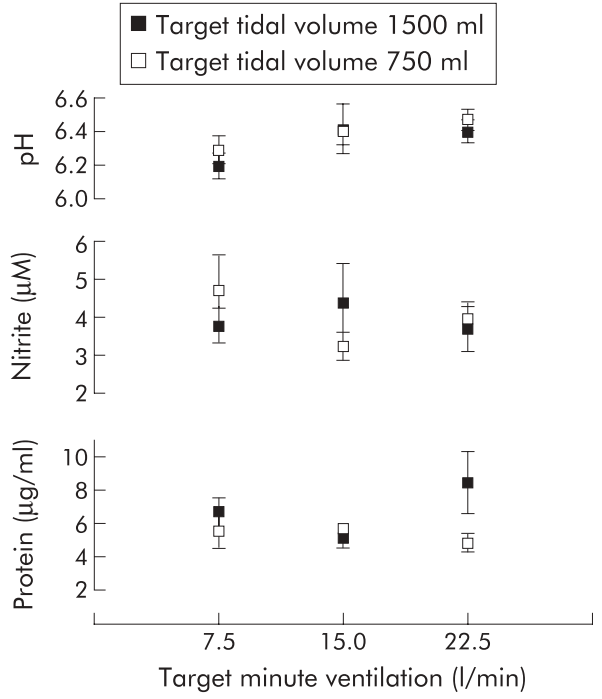

Figure 4 Mean $\mathrm{EBC}$ protein and nitrite concentrations and $\mathrm{pH}$ for each target minute ventilation $(\mathrm{Vm})$ and tidal volume $(\mathrm{Vt})$. Despite the effects of $\mathrm{Vm}$ and $\mathrm{Vt}$ on condensate volume (figs 2 and 3), Friedman's analysis of variance showed that $\mathrm{Vm}$ and $\mathrm{Vt}$ had no effect on EBC concentrations of protein, nitrite, or $\mathrm{pH}$ (all $\mathrm{p}>0.05$ ).

$1358 \mu \mathrm{l}$ for a 6 minute collection in the Vm range 7.5-22.5 $\mathrm{l} /$ min. This indicates that, for this collection device with subjects breathing at a typical resting $\mathrm{Vm}$ of $10 \mathrm{l} / \mathrm{min}$, a 6 minute collection would generate a sample of approximately $900 \mu \mathrm{l}$. The volume of TEW was significantly higher than the volume of EBC throughout the Vm range studied. This indicates that the condenser efficiency is far from $100 \%$ (range 40-29\%). It would be reasonable to suppose that this inefficiency also applies to the trapping of aerosolised droplets and that a device with improved efficiency would yield an increased quantity of solutes, thereby enhancing the sensitivity of this technique. A mean reduction of $962 \mathrm{ml}$ in Vt was associated with a $15 \%$ reduction in TEW for the same Vm; however, no corresponding effect was seen on solute dilution. This would imply that, at lower Vt, proportionally less solute is aerosolised for a given $\mathrm{Vm}$ and therefore the concentrations of solutes are maintained constant.

Inspired air conditions were found to have a small but significant effect on volumes of TEW and EBC. A fall in the inspired air temperature and humidity was associated with a reduction of up to $6 \%$ in TEW and $\mathrm{EBC}$, implying a similar degree of reduction in the dilution of solutes under cooler, drier conditions. However, this was not seen in the concentrations of nitrite and protein measured, probably because the effect-although significant-was small relative to the measurement error associated with assays of very small quantities of solutes. It is therefore unlikely that variations in inspired air conditions commonly encountered in the laboratory would account for significant measurement error.

The absence of an effect of ventilatory pattern on the protein concentration suggests that non-volatile solute concentrations are independent of breathing pattern. This is supported by the findings of Montuschi et $a l^{10}$ for 8isoprostane. $\mathrm{pH}$ is influenced by volatile solutes yet still showed no variance with breathing pattern, which suggests that breathing pattern is not an important determinant of either volatile or non-volatile solute concentrations in EBC. However, this finding is in contrast to the results of Schleiss et $a l^{9}$ for hydrogen peroxide in EBC. They proposed a bicompartmental model which argues that, if solute concentration is not flow dependent, then this would imply that solutes were arising from the more distal airway and alveolar region. An alternative explanation is that the aerosolisation is flow dependent, occurring in the proximal airway during inspiration and expiration with the net expiratory flux contributing to EBC. This process occurs in parallel with evaporation and condensation of water from the airway lining fluid, thereby maintaining constant the ratio of analyte to water vapour dilution.

For the purpose of comparison, the inspiratory to expiratory (IE) ratio in this study was set at $1: 1$ with subjects also being required to reproduce a square wave expiratory waveform. It is recognised that the ventilatory pattern is not solely defined by Vm and Vt, but that factors such as IE ratio and the shape of the inspiratory/expiratory flow rate signals may also be important in the context of airway water transport. Mathematical models of this complex process ${ }^{14}$ would suggest that a low IE ratio pattern would result in a lower expiratory water vapour concentration than a high IE pattern for the same Vt and Vm. It is also likely that the IE ratio will have an effect on the net flux of aerosolised droplets. Further studies are required to assess the significance of this effect on water vapour and analyte concentrations in EBC collections.

This study has shown that the effect of ventilatory pattern and inspired air conditions on exhaled water vapour and EBC volume to be significant but insufficient to explain the high degree of variability in solute concentrations seen in the studies by Effros et al ${ }^{8}$ and others. ${ }^{49}$ Likely sources of this variability include variation in aerosolisation, capture of droplets, and assay variability rather than water vapour dilution. Future attention must therefore be directed towards minimising these sources of variability in order to improve the overall sensitivity of this technique.

In conclusion, these results suggest that condensate yield can be significantly augmented by targeting the ventilatory pattern to higher tidal volumes $(>1000 \mathrm{ml})$ ) and minute ventilations over $15 \mathrm{l} / \mathrm{min}$. Such augmentation will not significantly affect analyte concentrations.

\section{ACKNOWLEDGEMENTS}

The authors acknowledge the contribution of Dr PA Kew and $\mathrm{Mr}$ A Haston, Department of Mechanical Engineering, Heriot-Watt University, Edinburgh for technical assistance with instrumentation, and Ms M Imrie, Respiratory Unit, Western General Hospital for assistance with nitrite and protein assays.

\section{Authors' affiliations}

J B McCafferty, T A Bradshaw, S Tate, A P Greening, J A Innes,

Respiratory Unit, Western General Hospital and University of Edinburgh, Edinburgh, UK

Funded by Chest, Heart and Stroke Scotland, UK

\section{REFERENCES}

1 Hunt JF, Fang K, Mlik R, et al. Endogenous airways acidification. Implication for asthma pathophysiology. Am J Respir Crit Care Med 2000; 161:694-9.

2 Hunt JF, Byrns RE, Ignarro $\amalg$, et al. Condensed expirate nitrite as a home marker for acute asthma. Lancet 1995:346:1235-6.

3 Corradi M, Folesani G, Andreoli R, et al. Aldehydes and glutathione in exhaled breath condensate of children with asthma exacerbation. Am J Respir Crit Care Med 2003;167:395-9.

4 Ho LP, Faccenda I, Innes JA, et al. Expired hydrogen peroxide in breath condensate of cystic fibrosis patients. Eur Respir J 2000;16:95-100.

5 Ho LP, Innes JA, Greening AP. Nitrite level in breath condensate of patients with cystic fibrosis is elevated in contrast to exhaled nitric oxide. Thorax 1998;53:680-4.

6 Dekhuijzen PN, Abben KK, Dekker I, et al. Increased exhalation of hydrogen peroxide in patients with stable and unstable chronic obstructive pulmonary disease. Am J Respir Crit Care Med 1996;154:813-6.

7 Montuschi P, Collins JV, Ciabattoni G, et al. Exhaled 8-isoprostane as an invivo biomarker of lung oxidative stress in patients with COPD and healthy smokers. Am J Respir Crit Care Med 2000;162:1175-7. 
8 Effros RM, Hoagland KW, Bosbous M, et al. Dilution of respiratory solutes in exhaled condensates. Am J Respir Crit Care Med 2002;165:663-9.

9 Schleiss MB, Holz O, Behnke M, et al. The concentration of hydrogen peroxide in exhaled air depends on expiratory flow rate. Eur Respir J 2000;16:1115-8.

10 Montuschi P, Kharitonov SA, Ciabattoni G, et al. Exhaled 8-isoprostane as a new non-invasive biomarker of oxidative stress in cystic fibrosis. Thorax 2000;55:205-9.
11 Gessner C, Kuhn H, Seyfarth HJ, et al. Factors influencing breath condensate collection. Pneumonologie 2001;55:414-9.

12 Ferrus L, Guenard H, Vardon G, et al. Respiratory water loss. Respir Physiol 1980;39:367-81.

13 Green LC, Wagner DA, Giogowski J, et al. Analysis of nitrate, nitrite and $\left[{ }^{15} \mathrm{~N}\right]$ in biological fluids. Anal Biochem 1982;126:131-8.

14 Ignito EP, Solway J, McFadden ER Jr, et al. Finite difference analysis of respiratory heat transfer. J Appl Physiol 1986;61:2252-9.

\section{LUNG ALERT}

The "hygiene hypothesis" revisited

$\Delta$ Benn CS, Melbye M, Wohlfahrt J, et al. Cohort study of sibling effect, infectious diseases, and risk of atopic dermatitis during first 18 months of life. BMJ 2004;328:1223-7

$\Delta$ Tulic MK, Fiset P-O, Manoukian JJ, et al. Role of toll-like receptor 4 in protection by bacterial lipopolysaccharide in the nasal mucosa of atopic children but not adults. Lancet 2004;363:1689-97

$\mathrm{T}$

he "hygiene hypothesis" suggests that decreasing exposure to micro-organisms during infancy is responsible for the increasing prevalence of atopy. However, while a decreased risk of atopic disease is associated with various surrogate markers of microbial exposure including early attendance at day care, a greater number of siblings and living on a farm, specific associations between clinical episodes of infection and atopy remain ill defined and the possible mechanisms obscure.

Two recent papers have sought to characterise further the links between infection and atopy. At a population level, Benn and colleagues used a series of four interviews to study 24341 mother-child pairs from 12 weeks gestation until the child was 18 months old. Relationships between atopic dermatitis and the incidence of clinically apparent infections were investigated. By 6 months of age $54 \%$ of children had experienced at least one infectious episode (most commonly a cold) and at the age of 18 months $11 \%$ of the children had atopic dermatitis. While inverse correlations between the presence of atopic dermatitis and a greater number of siblings, living on a farm, pet keeping, and early day care were confirmed, the occurrence of a clinically apparent infection did not result in a decreased risk of atopy. Indeed, the risk was slightly increased. Perhaps exposure to environmental organisms in the absence of clinically apparent disease is a more important phenomenon?

At a molecular level, Tulic and co-workers report the results of a study investigating the response of ex vivo nasal mucosal samples to stimulation with allergen in the presence and absence of lipopolysaccharide (LPS). The subjects comprised 22 children and 17 adults, both with and without atopy. LPS, a major component of gram negative bacterial cell walls, interacts with host tissue via the toll-like receptor TLR-4. This provides an important link between the innate and acquired immune responses and may be one way in which exposure to micro-organisms could modulate the subsequent risk of atopy. In the presence of LPS, allergen stimulation of the nasal mucosa from atopic children (but not adults) resulted in a Thl type response rather than the Th2 phenotype observed with allergen alone. This effect was shown to be mediated via TLR-4, with upregulation of the immunoregulatory cytokine interleukin-10. Since atopy is classically associated with a Th2 type response, the results suggest a mechanism by which exposure to microbial products might protect from atopic disease.

Debate surrounding the "hygiene hypothesis" continues. These two papers, rigorously conducted and using very different approaches, provide interesting insights into the possible underlying mechanisms.

J R Hurst

Lung Alert Editor, Thorax; jrhurst@lineone.net 